\title{
PCT - FERRAMENTA DE CONTROLE DA PRODUÇÃO E PROCESSO DO LTQ DA GERDAU OURO BRANCO*
}

\author{
Altair Lúcio de Souza ${ }^{1}$ \\ Anderson Vasconcelos Pires ${ }^{2}$ \\ Anderson Furieri ${ }^{3}$ \\ Alexandre Viana ${ }^{4}$ \\ João Júnio Pereira Lino ${ }^{5}$ \\ Willy Schuwarten Júnior ${ }^{6}$
}

\section{Resumo}

Foi implantado um software, PCT (Production Control Tool), de integração e coordenação do fluxo de dados entre os seguintes níveis de automação: nível 3, onde se encontram os dados de especificação do produto e sequenciamento de produção, e nível 2, onde se encontram os modelos matemáticos, resultados do processo, interface com medidores e rastreamento da produção. No processo de construção do PCT viu-se um grande potencial de desenvolver outras funcionalidades, devido enorme flexibilidade dessa ferramenta, como gerenciamento da produção, auxílio na inspeção de qualidade e controle estatístico do processo. Isto levou a criação de um sistema amigável de fácil utilização, utilizado tanto pelos operadores da Linha e inspetores de qualidade como também pelos analistas do processo, auxiliando na otimização da Linha de Tiras a Quente da Gerdau.

Palavras-chave: Níveis 2 e 3, Controle de Processo; Inspeção de Qualidade.

\section{PCT - PRODUCTION AND PROCESS CONTROL OF LTQ FROM GERDAU OURO BRANCO}

\begin{abstract}
The PCT (Production Control Tool) software was implemented to do the integration and management of data exchange between the following automation levels: Level 3 , which contains the product specification data and the production scheduling, and Level 2, where contains the mathematical models, process results, interface with meters and tracking of production. With the PCT implementation appeared a great potential to develop other features, because enormous flexibility of this tool, as production management, aid in quality inspection and statistical process control. This led to construction of a user-friendly system, used both by the operators of the line and quality inspectors as well as by process analysts, helping to optimize the hot strip mill of Gerdau.
\end{abstract}

Keywords: Interface Levels 2 and 3; Process Control; Quality Inspection.

1 Engenheiro Metalurgista/UFOP, Mestre em Metalurgia/UFMG, Assessor Técnico, Laminação de Tiras a Quente, Gerdau Ouro Branco, Ouro Branco, MG, Brasil (altair.souza@gerdau.com.br);

2 Engenheiro Eletricista/UFMG, Assessor Técnico, Manutenção Central, Gerdau Ouro Branco, Ouro Branco, MG, Brasil (anderson.pires@gerdau.com.br);

3 Engenheiro Eletricista/UFSJ, Especialista em Automação/UFMG, Assessor Técnico, Manutenção Central, Gerdau Ouro Branco, Ouro Branco, MG, Brasil (anderson.furieri@gerdau.com.br);

4 Engenheiro Eletricista/ UFMG, Gerente de Tecnologia da Geraes Integração de Sistemas, Belo Horizonte, MG, Brasil (alexandre@geraes.net);

5 Engenheiro Mecânico/UNILESTE, Mestre em Metalurgia/UFOP, Assessor Técnico, Laminação de Tiras a Quente, Gerdau Ouro Branco, Ouro Branco, MG, Brasil, (joao.lino@gerdau.com.br);

6 Engenheiro Mecânico/UNILESTE, Mestre em Metalurgia/UFMG, Gerente da Laminação de Tiras a Quente, Gerdau Ouro Branco, Ouro Branco, MG, Brasil (willy.schuwarten@gerdau.com.br). 


\section{INTRODUÇÃO}

A Linha de Tiras a Quente da Gerdau entrou em operação no mês de Outubro de 2013. Esta Linha é dotada de modernos equipamentos com seus sistemas de automação e respectivos modelos matemáticos e atuadores dinâmicos para atender a produção de bobinas de aço carbono e microligados de faixa de espessura 1,80 a $25,40 \mathrm{~mm}$ e largura 860 a $2100 \mathrm{~mm}$. A figura 1 mostra um desenho esquemático da Linha de Tiras a Quente da Gerdau destacando os seus principais equipamentos.

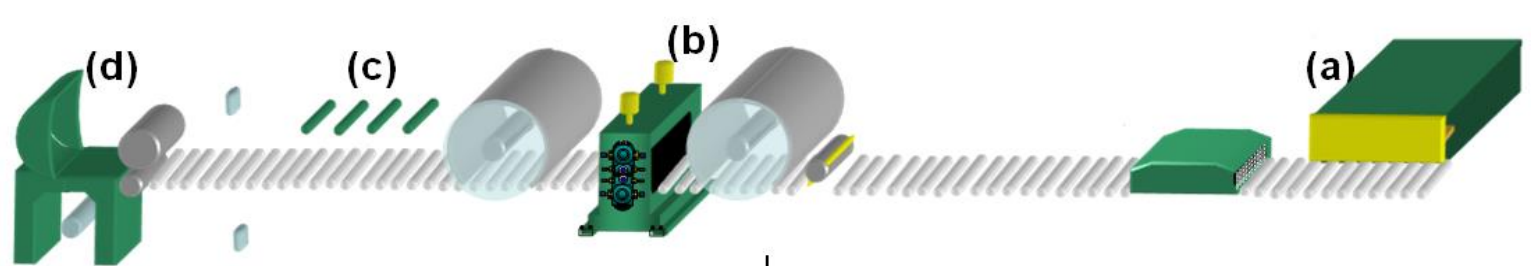

Figura 1. Linha de Tiras a Quente da Gerdau: (a) Forno de Reaquecimento; (b) Laminador Quádruo Reversível tipo Steckel; (c) Sistema de Resfriamento; (d) Bobinadeira.

Para garantir a continuidade do processo produtivo é necessário que os dados de entrada, chamados dados de PDI (Primary Data Input) estejam plenamente disponibilizados e sejam consistentes, pois podem afetar o setup dos equipamentos (forno, laminador, sistema laminar e bobinadeira) e gerar danos à Linha, má qualidade de produto e sucatas no processo.

Os dados de saída do processo, chamados dados de PDO (Production Data Output) são utilizados para a finalização do produto. $O$ armazenamento desses dados por longos períodos é de suma importância, pois são utilizados para análise e otimização do processo e na avaliação de eventuais reclamações de clientes. Normalmente o período de armazenamento de dados no nível 2 é curto, devido o uso da memória desse sistema concorrer com os cálculos executados durante o processo (modelo matemático, medições, tracking etc.), logo, os dados devem ser enviados para outros níveis para armazenamento por um período maior.

A função básica do PCT é servir como uma solução robusta de comunicação entre os níveis 3 e 2 de automação, efetuando o envio de PDI aos sistemas de nível 2 e o envio de PDO aos sistemas de nível $3^{[1]}$. A figura 2 mostra a hierarquia dos níveis de automação ${ }^{[2,3]}$ e onde se encontra inserido o PCT.

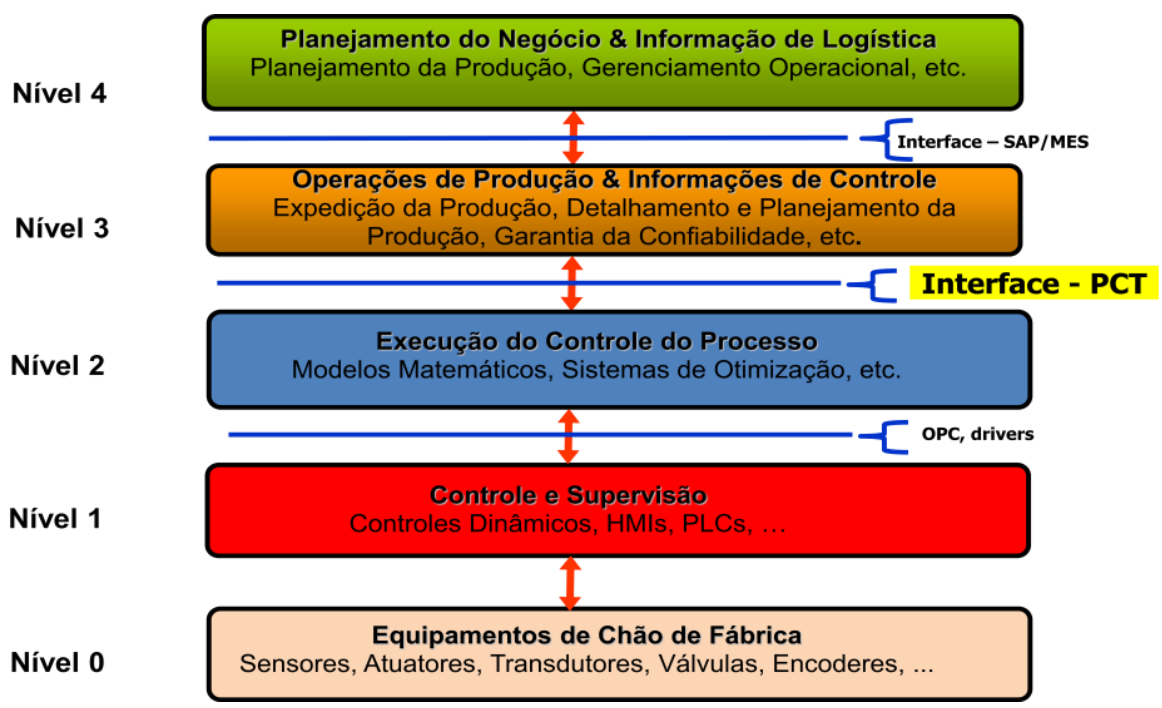

Figura 2. Hierarquia dos sistemas de automação 
Nesse trabalho apresentam-se algumas das principais funcionalidades que foram desenvolvidas no PCT com os seguintes objetivos: garantia de transferência de dados entre os níveis 2 e 3 de automação, monitoramento e gerenciamento do processo de produção, auxílio na inspeção de qualidade dos produtos e no controle estatístico do processo.

\section{FUNCIONALIDADES DO PCT}

No processo de construção do PCT foram criadas funcionalidades em diferentes telas para facilitar o gerenciamento de informações entre os níveis de automação e promover de forma simples e rápida a análise e controle do processo.

Todas as telas têm o cabeçalho com link de acesso a cada um dos ambientes disponíveis, e as pastas de comandos na vertical em comum a outras telas, habilitados por chaves de permissões por competência do usuário e local de trabalho. A figura 3 mostra uma das telas do sistema onde podemos visualizar os comandos e links existentes.

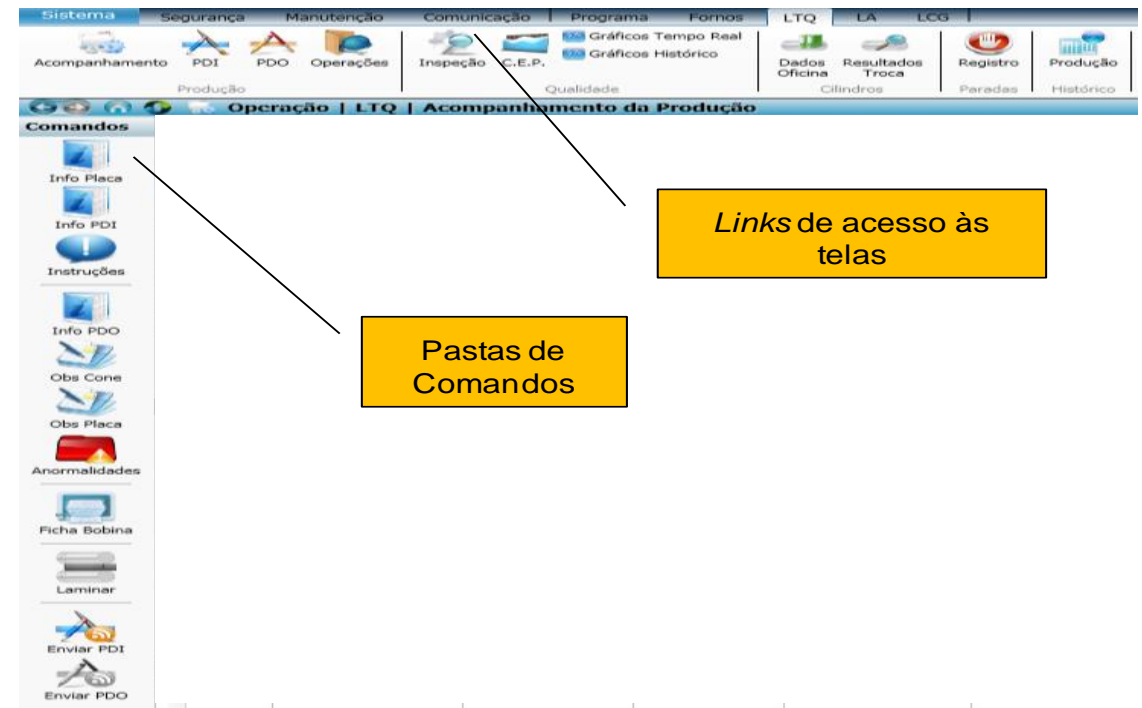

Figura 3. Pastas de comandos e links de acesso às telas

A seguir serão apresentadas algumas das principais funcionalidades implantadas nesse sistema.

\subsection{Ferramentas para Gerenciamento de Informações}

Foi desenvolvida uma tela específica para gerenciamento das informações transferidas entre os níveis 2 e 3 de automação. Nesse ambiente permite visualizar os dados completos de PDI e PDO acessando-se seus respectivos telegramas XML. A cada mensagem enviada ou recebida a tela é atualizada mostrando em tempo real o status da comunicação, se enviada, recebida, tratada ou recusada (erro). Em caso de comunicação com erro, nessa tela também é informado qual sistema a mensagem não foi tratada (nível 2 ou nível 3).

Para evitar erros de comunicação, o PCT apresenta os limites válidos para cada parâmetro, gerando mensagem de falha quando estes limites são extrapolados em determinado nível, rejeitando a mensagem. O próprio operador da Linha de produção pode acessar esta tela, visualizar a mensagem de erro e informar o motivo da falha aos analistas de automação (TI: Tecnologia de Informação e TA: Tecnologia 
de Automação) para tomarem as devidas providências e reestabelecer os sistemas, evitando assim paradas desnecessárias da produção.

No caso de erro de PDI (dimensões, peso, dados visados do processo etc.) de uma peça programada para a produção, a mesma fica destacada em vermelho no PCT e indisponível para as operações de identificação, enfornamento e laminação enquanto o erro não for corrigido ou a peça for rejeitada do programa. Isto evita o enfornamento de material que pode gerar um produto não conforme ou até mesmo comprometer o setup dos equipamentos.

A figura 4 apresenta a tela de comunicação onde pode ser visualizado o telegrama XML de uma peça que apresentou erro (destacada em vermelho), e a descrição do erro de tratamento para a peça selecionada.

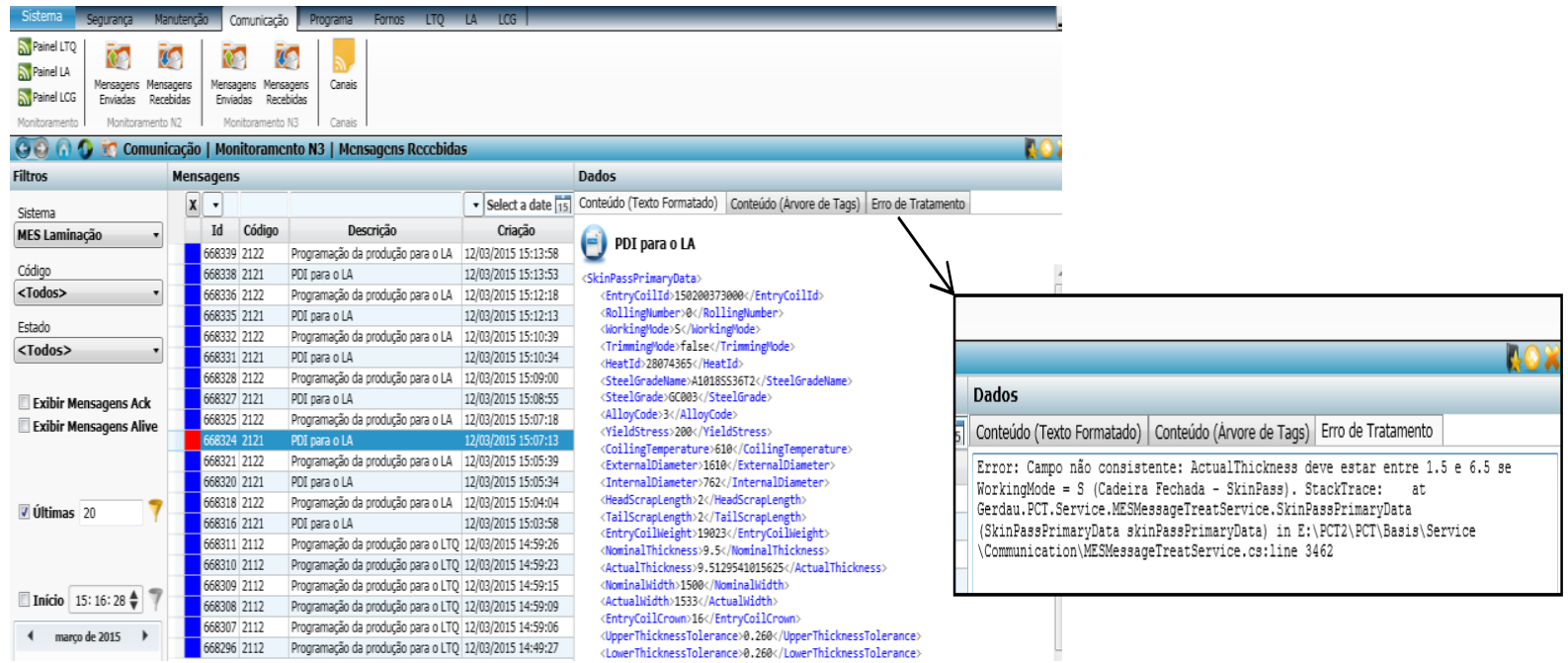

Figura 4. Tela de comunicação apresentando os dados recebidos e mensagem de erro

\subsection{Acompanhamento Operacional}

Nas telas operacionais, que são as telas do Forno e LTQ (Laminador) são visualizadas as peças programadas ou em processo, com um padrão de cores que identifica o status do material, se programado (sem cores), identificado (verde), enfornado (vermelho), produzido (azul) e rejeitado (amarelo). A exibição das colunas com os dados das peças é configurável, ou seja, o usuário pode escolher quais colunas deseja exibir, entre os dados disponíveis para cada tela.

Existe em cada tela a opção de filtro por cone (programa de laminação por campanha de cilindro de trabalho), número de peça (placa ou bobina), últimas e próximas enfornadas ou laminadas e peças rejeitadas. Além disso, cada coluna apresenta filtro individual. Todos os dados da tela selecionada podem ser exportados nas extensões de arquivos csv ou $x / s$.

A figura 5 apresenta um exemplo de tela operacional do LTQ com as peças enfornadas (vermelho) e laminadas (azul). 


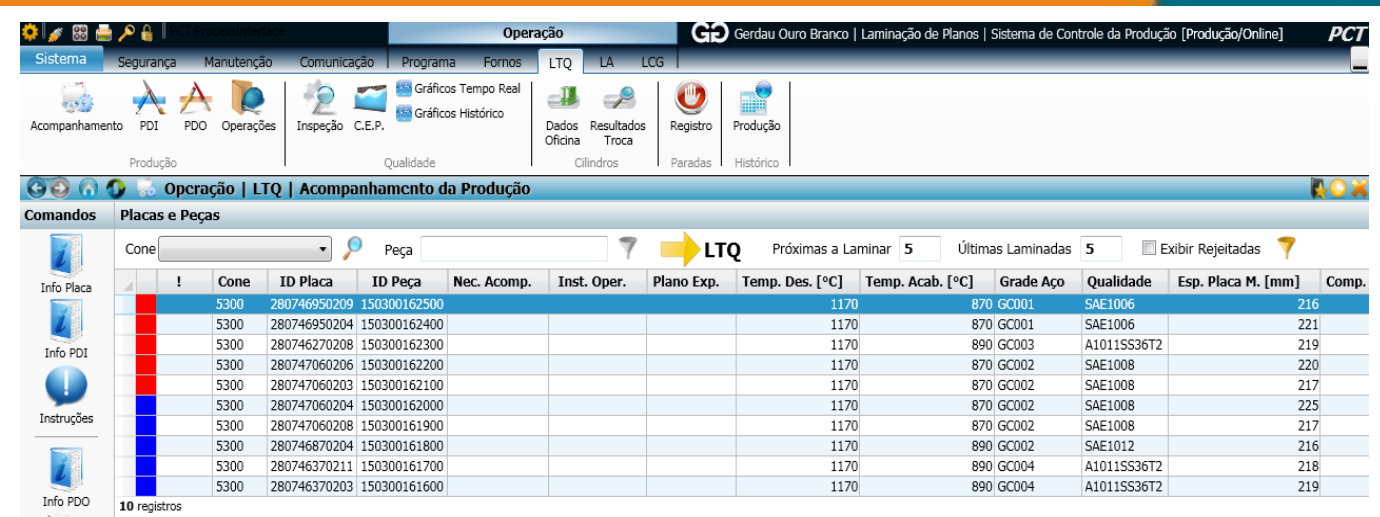

Figura 5. Tela operacional do LTQ

Em cada tela operacional é possível acrescentar notas (mensagens de texto), pelos comandos "Obs. Cone", "Obs. Peça" ou inserir códigos de anormalidades, pelo comando "Anormalidades" para cada peça ou cone. Estas informações auxiliam na inspeção de qualidade e análise do processo.

\subsection{Acompanhamento de dados de entrada (PDI)}

Para cada processo (Forno ou LTQ) o usuário pode solicitar a tela de visualização do PDI de cada peça. Nessa tela pode ser efetuada a edição de alguns dados de PDI. Essa funcionalidade é útil, por exemplo, no caso de desenvolvimento de novos produtos onde se deseja testar diferentes parâmetros de laminação para ver a influência desses na propriedade mecânica, ou seja, ao invés de criar diferentes especificações para esse produto em desenvolvimento, utiliza-se apenas uma e fazse a edição dos parâmetros das peças a serem testadas. A figura 6 mostra a tela de PDI do LTQ.

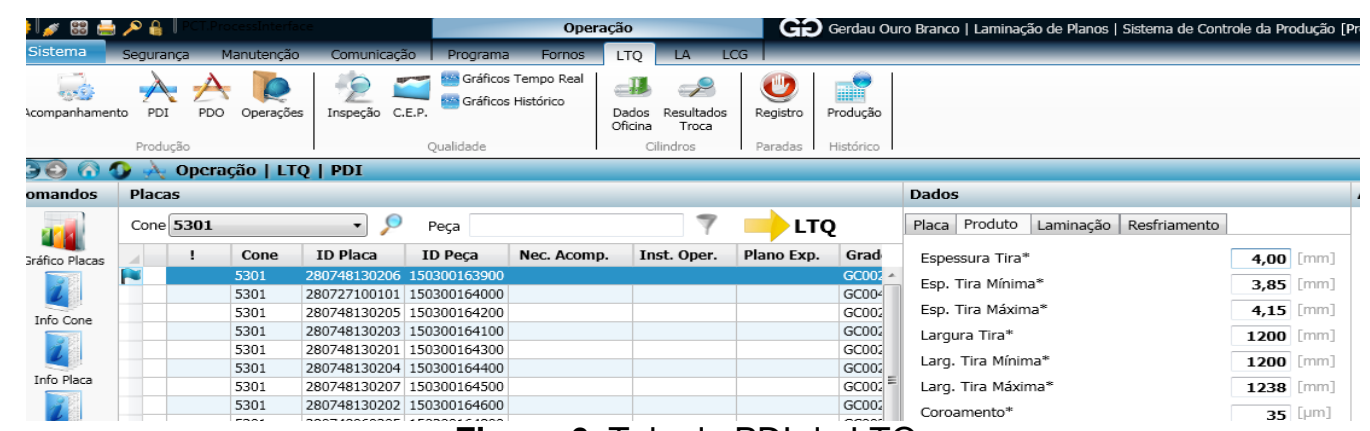

Figura 6. Tela de PDI do LTQ.

\subsection{Acompanhamento dos dados de saída (PDO)}

Os dados PDO são de suma importância para, entre outras aplicações, auxiliar na análise e desenvolvimento dos produtos e processos. Os principais dados consolidados do processo, como força, torque, velocidade, temperaturas, esquema de passe entre outros foram selecionados e indicados para serem armazenados no PCT. Isto permite uma detalhada análise do processo, de falhas na laminação, de eventuais ocorrências de sucatas, de desvios de qualidade, de reclamações de cliente etc.

A figura abaixo mostra a tela de PDO do LTQ para uma determinada peça selecionada. Os dados são divididos por grupos de grandezas do produto, como Largura, Coroamento, Temperaturas etc. 


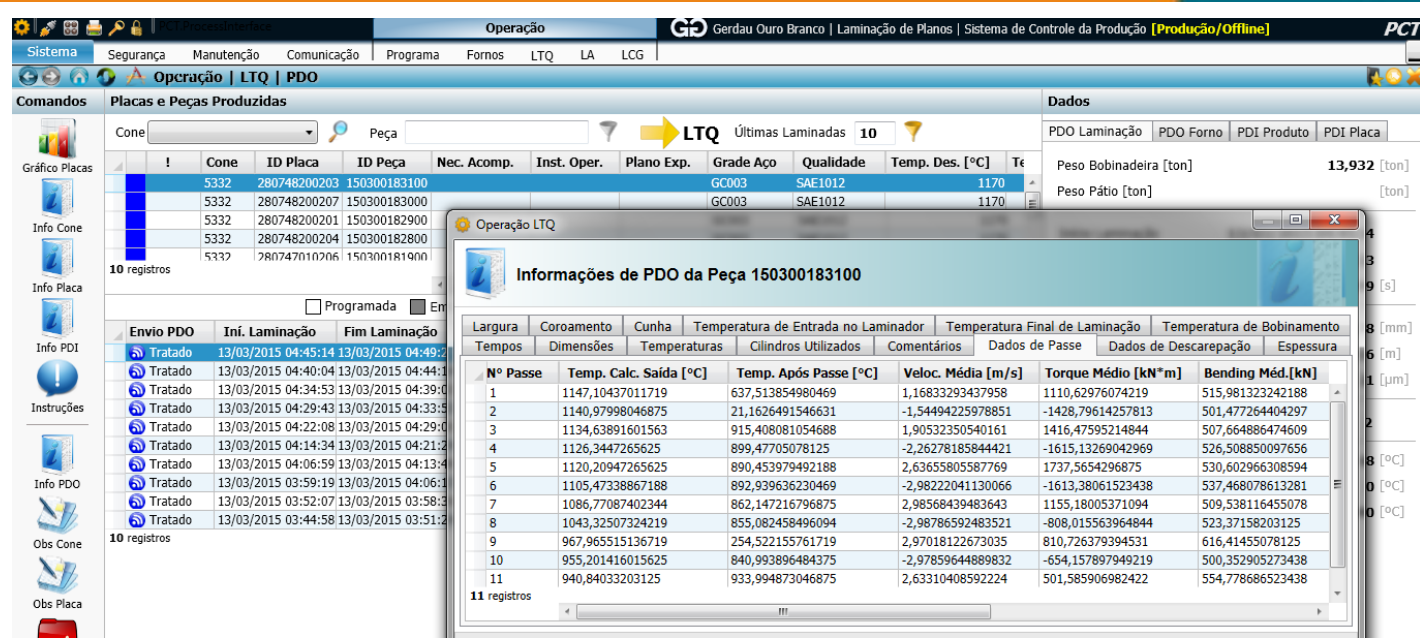

Figura 7. Tela de PDO do LTQ

Os resultados de cada peça produzida também podem ser visualizados pela ficha da bobina, que apresenta de forma consolidada todos os dados de PDO e PDI da peça selecionada, e é gerada no formato para impressão ou planilha Excel.

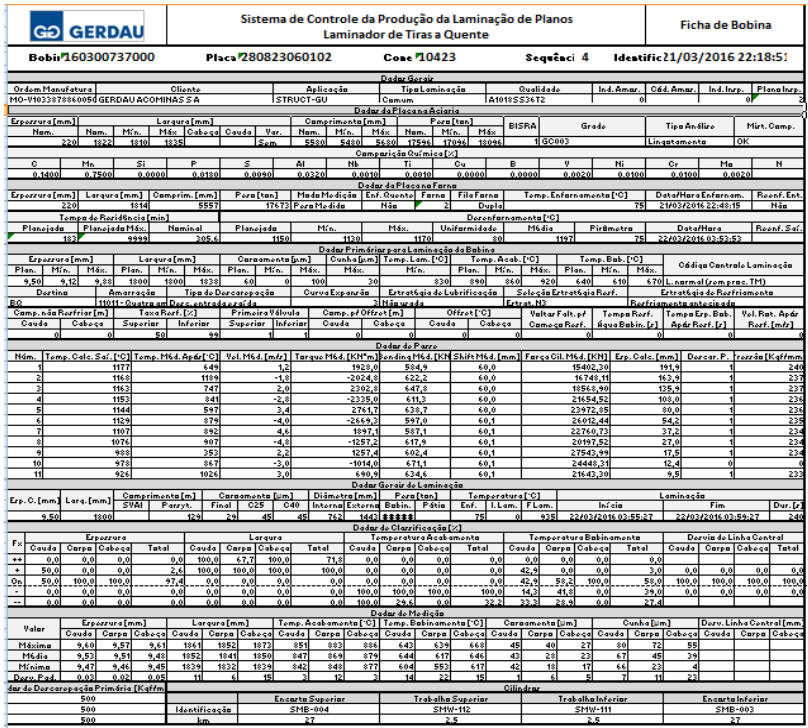

Figura 8. Ficha de bobina

\subsection{Telas de Inspeção}

Para auxiliar na aprovação ou rejeição das bobinas produzidas na Linha de Tiras a Quente, foram criadas as telas de inspeção e as telas contendo os gráficos com os resultados dos medidores do processo (espessura, largura, temperatura de entrada, temperatura de acabamento, temperatura de bobinamento, coroamento, cunha, desvio de centro e planicidade). A tela de gráficos serve também como um historiador dos medidores instalados na Linha. Nessas telas podem também serem exibidas as tolerâncias de especificação do cliente, destacando em vermelho os pontos fora das tolerâncias, auxiliando na tomada de decisão do inspetor de qualidade.

Já existem alguns gráficos configurados para rápido acesso do usuário, ou, se o mesmo desejar pode configurar quantos gráficos (até quatro gráficos) e quais grandezas deseja exibir na tela. Dependendo da pesquisa efetuada, pode-se exibir mais de uma peça ao mesmo tempo (uma em cada gráfico disponível). 
A figura 9 mostra uma visualização das telas gráficas do PCT destacando os ícones para configuração de exibição dos gráficos na tela.

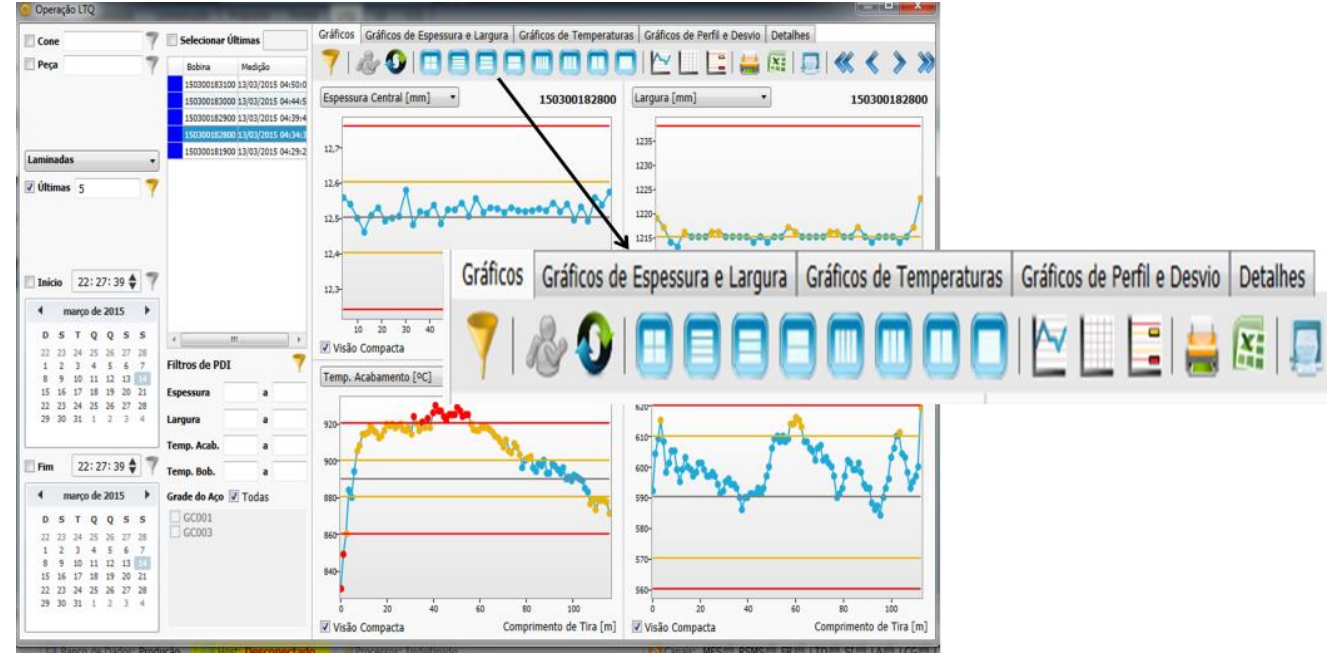

Figura 9. Exemplo de telas gráficas do PCT

São diversas as possibilidade de pesquisa no histórico dos gráficos, pode ser por número de programa de produção (cone), pelo número da peça (placa ou bobina), selecionando as últimas laminadas e por período de data. O banco de dados gerado na pesquisa pode ser ainda filtrado por faixa de espessura, faixa de largura, temperatura de acabamento, temperatura de bobinamento e grade do aço.

Todos os dados que geram os gráficos também podem ser exportados para cada peça para extensão xls ou csv.

\subsection{Controle Estatístico do Processo}

Foi criada a tela de CEP (Controle Estatístico do Processo) para auxiliar no estudo da capabilidade do processo. Nessa tela são visualizados vários dados de especificação do produto e os resultados dos medidores da Linha: medidores da entrada do forno (largura, comprimento, espessura, temperatura de enfornamento) e saída do laminador (espessura, largura, cunha, coroamento, desvio de centro, temperatura de acabamento e bobinamento). Os dados dos medidores de saída do laminador são apresentados em valores médios, máximos, mínimos, desvio padrão e porcentagem dentro das faixas de tolerância (faixa de tolerância do cliente e faixa do processo) para diferentes partes da tira laminada (cabeça, corpo e cauda). Como as faixas de tolerâncias podem variar por norma especificada ou negociação com cliente para uma mesma dimensão, foram criadas as faixas de processo, para ajudar na análise da capabilidade da Linha.

A tela de CEP também pode apresentar, de maneira gráfica, a tendência de determinados parâmetros do processo, auxiliando o operador do laminador a tomar ações corretivas durante a laminação. Ex.: se selecionar a evolução dos resultados de coroamento e for constatada alguma tendência crescente ou decrescente, 0 operador pode mudar a curva de shifting (movimentação horizontal do cilindro de trabalho) aplicada para corrigir o desvio visualizado. 


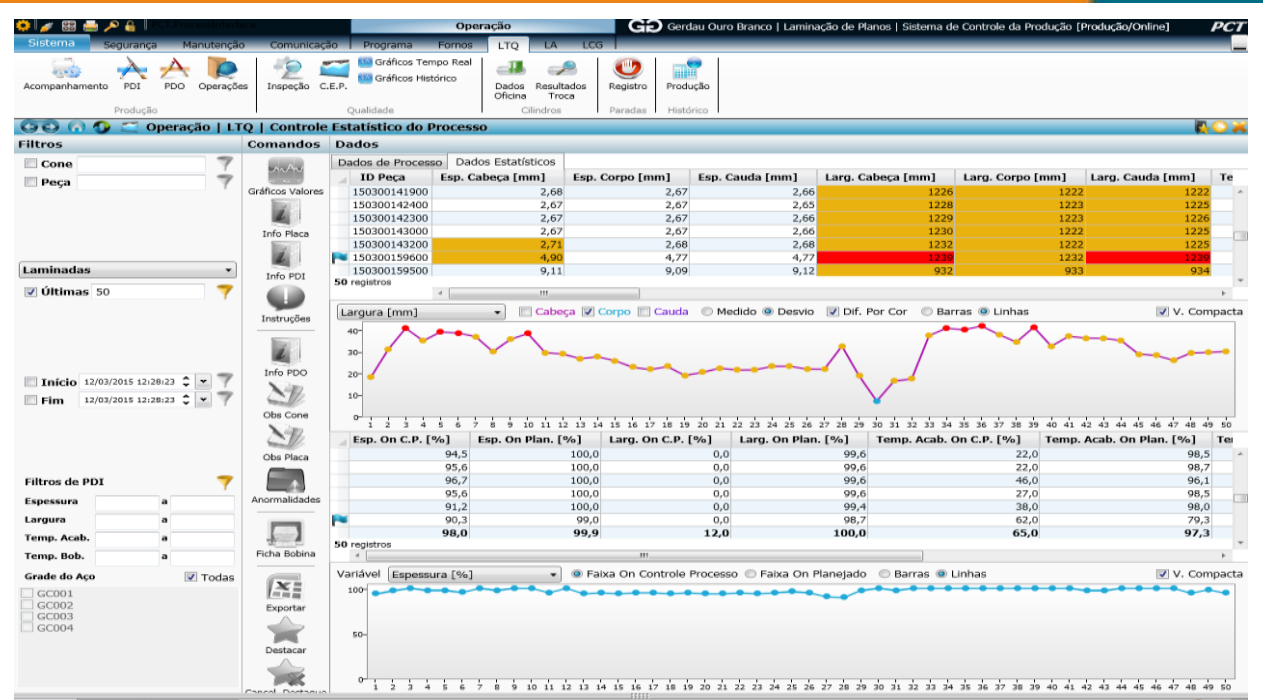

Figura 10. Tela de controle estatístico do processo

\subsection{Ferramentas para Gerenciamento da Produção e Qualidade}

Foram desenvolvidas telas para assistência no controle de produção. Permite ao gestor avaliar a produção diária, turno a turno, mensal, incluindo o volume produzido, sucatado, retornado e rejeitado. Essas informações alimentam os índices mensais de produção. A tela abaixo apresenta a evolução da produção.

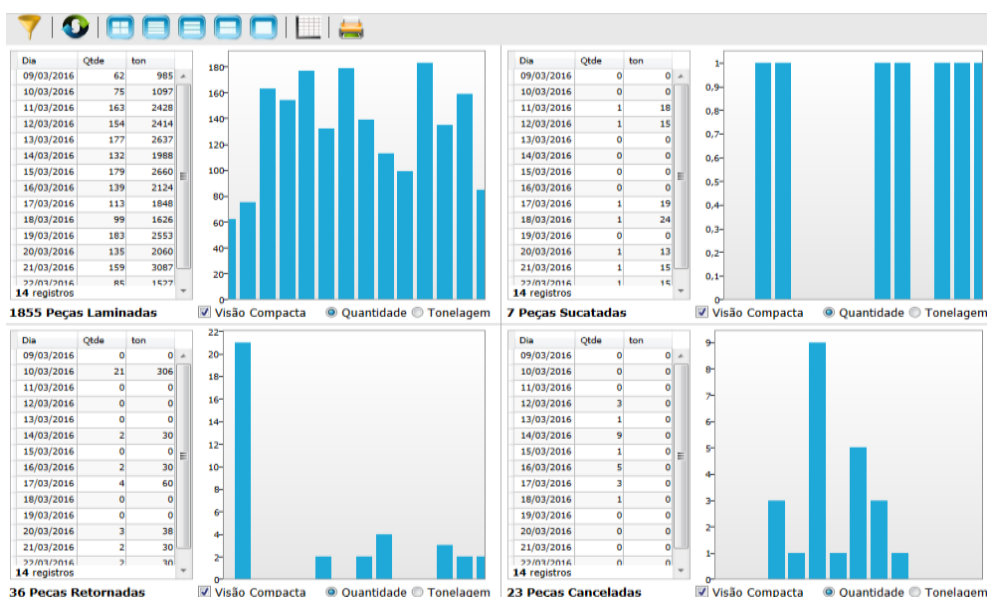

Figura 11. Tela de acompanhamento da produção

Pode-se ainda acompanhar o status das peças produzidas com resultado de inspeção. Se aprovadas, pendentes, sucatas ou retrabalho conforme exemplo mostrado na figura 12.

$\oplus$

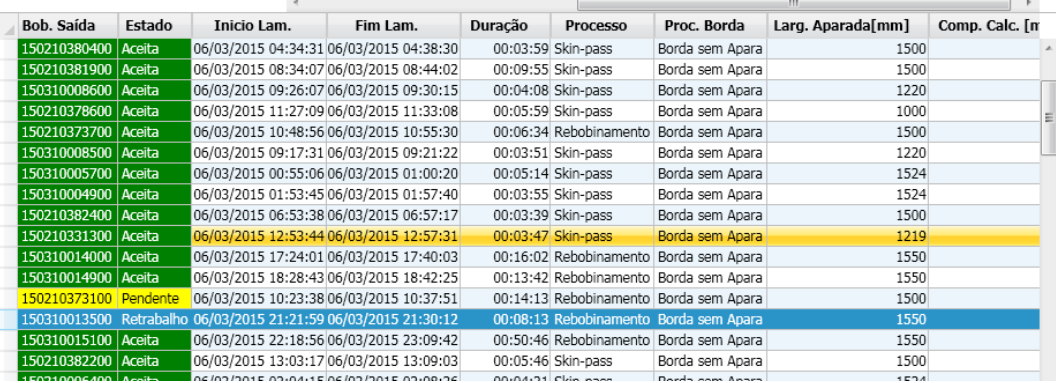

Figura 12. Tela de acompanhamento do resultado de qualidade 


\section{CONCLUSÃO}

As funcionalidades implantadas no PCT têm se mostrado muito úteis para gerenciamento e controle do processo da Linha de Tiras a Quente da Gerdau. Os relatórios e gráficos gerados nesse sistema têm auxiliado na garantia de qualidade especificada pelo cliente, na otimização do processo e no desenvolvimento de novos produtos. Todos os operadores da Linha conseguem navegar facilmente nas diversas telas desenvolvidas, o que demonstra que é uma ferramenta de interface amigável e prática para uso industrial.

Melhorias continuam sendo implantadas no PCT e os resultados obtidos até aqui demonstram a importância do trabalho em conjunto envolvendo as equipes de Operação e Automação.

\section{REFERÊNCIAS}

1 Especificação Geral do PCT; GERDAU; Ouro Branco; 2011

2 Architecture of Industrial Automation System; Version 2 EE IIT, Kharagpur

3 Machado, MLP, Introdução ao Controle e Automação, Vitória, Espírito Santo; CEFET; 2006. 